\title{
Narcissism and Social Networking Web Sites
}

\author{
Laura E. Buffardi \\ W. Keith Campbell \\ University of Georgia
}

The present research examined how narcissism is manifested on a social networking Web site (i.e., Facebook.com). Narcissistic personality self-reports were collected from social networking Web page owners. Then their Web pages were coded for both objective and subjective content features. Finally, strangers viewed the Web pages and rated their impression of the owner on agentic traits, communal traits, and narcissism. Narcissism predicted (a) higher levels of social activity in the online community and (b) more selfpromoting content in several aspects of the social networking Web pages. Strangers who viewed the Web pages judged more narcissistic Web page owners to be more narcissistic. Finally, mediational analyses revealed several Web page content features that were influential in raters' narcissistic impressions of the owners, including quantity of social interaction, main photo selfpromotion, and main photo attractiveness. Implications of the expression of narcissism in social networking communities are discussed.

Keywords: narcissism; social networking Web sites; Internet; self-presentation

$\mathrm{T}$ he migration of individuals, especially teenagers and young adults, onto the Internet has occurred in staggering proportions. In particular, social networking Web sites-nonexistent just years ago-have drawn literally millions of users. Web sites such a MySpace .com (total users: 90 million per month; Stone, 2007) and Facebook.com (total users: 21 million members; Geist, 2007) have been at the forefront of this migration. These Web sites offer individuals the abilities, among others, to (a) create an individual Web page, (b) post self-relevant information (e.g., self-descriptions, photos), (c) link to other members (e.g., "friends lists"), and (d) interact with other members.
Recently, there has been a tremendous amount of attention in the media surrounding the issue of narcissism and social networking Web sites (e.g., Baldwin \& Stroman, 2007; Orlet, 2007; Vaidhyanathan, 2006). The concern is that these Web sites offer a gateway for self-promotion via self-descriptions, vanity via photos, and large numbers of shallow relationships (friends are counted-sometimes reaching the thousands-and in some cases ranked), each of which is potentially linked to trait narcissism.

The vast popularity of these sites suggests that the general psychology of the members will be largely normative. That is, the 21 million members of Facebook arguably (although it is, of course, still an empirical question) look similar to others in society with similar demographics. This was not necessarily the case in the past and still might not be the case with lower base rate Web presences, like freestanding personal Web pages. For example, a study published in 2006 showed that owners of personal Web sites did differ from controls on several dimensions of the Big Five, and women, but not men, did differ in narcissism with female Web page owners reporting the higher narcissism scores (Marcus, Machilek, \& Schütz, 2006). ${ }^{1}$

Our focus will thus not be on the mean-level narcissism score of the average social networking Web site user. Instead, we will address the question of how narcissism is manifested in these sites: Does narcissism predict

Authors' Note: We would like to thank Laura Aikens, Laura Aquilino, Joel Frost, Jesse Hauch, Abby Levin, and Ben Porter for their assistance with data collection and coding. Please address correspondence to Laura E. Buffardi or W. Keith Campbell, Department of Psychology, University of Georgia, Athens, GA 30602-3013; e-mail: lbuffardi@gmail.com or wkeithcampbell@gmail.com.

PSPB, Vol. 34 No. 10, October 2008 1303-1314

DOI: $10.1177 / 0146167208320061$

(C) 2008 by the Society for Personality and Social Psychology, Inc. 
overall activity in a Web community? Is narcissism apparent in the content of the Web page, and if so, how? Finally, can the narcissism of a page owner be gleaned from the content of the Web page? Before discussing our design in detail, we briefly describe the construct of narcissism, review the literature on the social qualities of the Internet, and specify our predictions.

\section{Narcissism and Social Behavior}

Narcissism refers to a personality trait reflecting a grandiose and inflated self-concept. Specifically, narcissism is associated with positive and inflated self-views of agentic traits like intelligence, power, and physical attractiveness (Brown \& Zeigler-Hill, 2004; Campbell, Rudich, \& Sedikides, 2002; Gabriel, Critelli, \& Ee, 1994; John \& Robins, 1994) as well as a pervasive sense of uniqueness (Emmons, 1984) and entitlement (Campbell, Bonacci, \& Shelton, 2004). ${ }^{2}$ From a basic trait perspective, narcissism is associated with a high degree of extraversion/agency and a low level of agreeableness or communion (e.g., Miller \& Campbell, 2008; Paulhus \& Williams, 2002). A similar high agency pattern (and negative but typically small/nonsignificant correlations with communion) is also found in narcissists' explicit self-conceptions (Campbell, Foster, \& Finkel, 2002), implicit self-conceptions (Campbell, Bosson, Goheen, Lakey, \& Kernis, 2007), and implicit motives (Carroll, 1987).

Central to most theoretical models of narcissism in social-personality psychology is the use of social relationships in part to regulate self-esteem, self-concept positivity, or narcissistic esteem (Campbell, 1999; Campbell, Brunell, \& Finkel, 2006; Morf \& Rhodewalt, 2001; Raskin, Novacek, \& Hogan, 1991). Narcissists do not focus on interpersonal intimacy, warmth, or other positive long-term relational outcomes, but they are very skilled at both initiating relationships and using relationships to look popular, successful, and high in status in the short term. Narcissists participate in this dynamic "self-construction" (Morf \& Rhodewalt, 2001) via relationships to constantly affirm their narcissistic esteem. It has been suggested that this process is due, at least partially, to narcissists' dispositional impulsivity (Vazire \& Funder, 2006). How does this narcissistic self-regulation or self-construction (we use these terms largely interchangeably) operate in the context of interpersonal relationships more specifically? First, narcissism is linked positively with relationship formation. For example, narcissism is associated with being (a) liked in initial interactions (Oltmanns, Friedman, Fiedler, \& Turkheimer, 2004; Paulhus, 1998), (b) perceived as a leader (Brunell, Gentry, Campbell, \& Kuhnert, 2006), (c) perceived as exciting (Foster, Shrira, \& Campbell, 2003), (d) socially confident (Brunell, Campbell, Smith, \& Krusemark, 2004), (e) entertaining (Paulhus, 1998), and (f) able to obtain sexual partners (Foster, Shrira, \& Campbell, 2006). Second, narcissism is associated negatively with seeking out or creating long-term relationships that have qualities of closeness, empathy, or emotional warmth (Brunell et al., 2004; Campbell, 1999; Campbell \& Foster, 2002). Third, narcissism is associated with using relationships as an opportunity or forum for selfenhancement. For example, narcissists brag and show off (Buss \& Chiodo, 1991), perform well when there is an opportunity for public glory (Wallace \& Baumeister, 2002), and seek attractive, high-status, "trophy" romantic partners (Campbell, 1999). Others in relationships with narcissistic individuals, however, often suffer in the longer term as narcissism is linked to aggressiveness (Bushman \& Baumeister, 1998), psychological control (Campbell, Foster, et al., 2002), game playing and infidelity (Campbell, Foster, et al., 2002; Le, 2005; Schmitt \& Buss, 2001), and lower levels of commitment (Campbell \& Foster, 2002). Indeed, longitudinal research on relationships has found that the initial likeability associated with narcissism fades and is even reversed in the longer term (Paulhus, 1998). Similarly, longitudinal research in clinical settings has found a significant long-term consequence of narcissism is the suffering of close others (Miller, Campbell, \& Pilkonis, 2007).

How might narcissism operate in a social networking Web site? These online communities may be an especially fertile ground for narcissists to self-regulate via social connections for two reasons. First, narcissists function well in the context of shallow (as opposed to emotionally deep and committed) relationships. Social networking Web sites are built on the base of superficial "friendships" with many individuals and "sound-byte" driven communication between friends (i.e., wallposts). Certainly, individuals use social networking sites to maintain deeper relationships as well, but often the real draw is the ability to maintain large numbers of relationships (e.g., many users have hundreds or even thousands of "friends"). Second, social networking Web pages are highly controlled environments (Vazire \& Gosling, 2004). Owners have complete power over self-presentation on Web pages, unlike most other social contexts. In particular, one can use personal Web pages to select attractive photographs of oneself or write self-descriptions that are self-promoting. Past research shows that narcissists, for example, are boastful and eager to talk about themselves (Buss \& Chiodo, 1991), gain esteem from public glory (Wallace \& Baumeister, 2002), are prevalent on reality television (Young \& Pinsky, 2006), and enjoy looking at themselves on videotape and in the mirror (Robins \& John, 1997). Personal Web pages should present a similar opportunity for self-promotion. 
In sum, given the behaviors of narcissists in offline relationship contexts, we expect that they will take advantage of the new virtual arena for pursuing a similar self-regulatory agenda. This will include relatively high levels of relationship formation, self-promoting images of oneself, and an overall agentic (rather than communal) self-presentation.

\section{Personality Manifestation on Web Pages}

To what extent will Web page observers be able to estimate Web page owners' narcissism? In order to make predictions about the expression of narcissism on Web pages, it is important to ask two broader questions: Is personality, in general, apparent on personal Web pages? And if so, how is personality inferred from Web pages?

Past research has shown that personality can be accurately detected from Web pages and that this detection is linked to specific Web page content (e.g., Marcus et al., 2006; Vazire \& Gosling, 2004). For example, research concerning self-presentation on the Internet has shown that Web site viewers tend to make appropriate inferences about owners' Big Five personality based on personal Web pages, particularly with regard to Openness to Experience (Marcus et al., 2006; Vazire \& Gosling, 2004). Correlations between individuals' actual personality scores and the perceptions of these personality dimensions drawn from their Web sites were similar in magnitude to those impressions drawn from other personality-reflective but nonelectronic contexts (e.g., their bedrooms; Vazire \& Gosling, 2004).

In addition, evidence suggests that Web page viewers utilize page content to form impressions of owners' personalities. Marcus and colleagues (2006) found that Web site features relevant to each of the Big Five personality dimensions correlated with viewers' impressions of the owners' Big Five personalities. For example, a couple of the correlations observed in this study are as follows: (a) Impressions of high Extraversion correlated with the number of photographs owners posted picturing themselves with other individuals and themselves at parties, and (b) Conscientious Web page owners tended to post their resumes and count the number of visitors to their sites.

In sum, past research suggests that personality factors are (a) somewhat accurately expressed by Web page owners through personal Web page content and (b) appropriately inferred by Web site viewers. These findings give us reason to expect that narcissism will also be expressed by Web page owners and inferred by Web page viewers based on Web page content.

\section{The Present Research}

The goal of this study was to examine the role of narcissism in personal Web pages on social networking sites. We were particularly interested in social networking Web sites rather than other types of personal Web pages for two reasons. First, they are a venue for both self-presentation and social interaction. Social networking sites are designed for not only conveying information about one's self to others but also, to a greater extent than other forms of personal Web sites, for being social online. Second, social networking sites are extremely popular and are still growing in popularity.

There are a number of social network sites available to Internet users; among the most widely used are MySpace.com, Friendster.com, and Facebook.com. We chose Facebook for our investigation for two reasons. First, Facebook is the most commonly used site by individuals in our sample-college students. Facebook.com was originally designed as a way for college students to electronically communicate with other students at their own university and, later, with others across the country. When it was first created, a university e-mail address was required to register and to set up an account. Although now all e-mail addresses are granted accounts, Facebook.com remains popular with college students (about half of its members are in college; Kirkpatrick, 2007). Second, Facebook is the most structured social network Web site. That is to say, Facebook profile pages have a fixed format and this consistency allows for a more controlled comparison of Web pages. A Facebook page utilizes a fill-in-the-blank system of personalization. All pages share common social characteristics, such as links to friends' pages, membership in virtual groups, and an electronic bulletin board, called the wall, where friends post messages to the owner. Facebook pages also have sections designated for the owner's self-presentation. In a section titled About $\mathrm{Me}$, page owners typically describe themselves and their likes and dislikes. Another section is designated for Quotes. This is where page owners list their favorite quotes, either from literature, popular culture, or funny anecdotes from real-life conversations. Uploaded photographs are the other main self-presentational element of a Facebook page. The owner's main picture appears the most frequently. It is dominant on the page in size and appears on every wallpost the owner makes and each time the owner comes up in a member search. Albums are a subsidiary feature that act as an online photo gallery and typically include pictures of friends, parties, trips, and so on. Since the data for this study were collected, Facebook has evolved (Locke, 2007). Although the main features discussed here remain prominent, users now have more options in the structure and content of their profiles. Researchers who plan to use Facebook in future research should be aware of these changes. 
Our investigation consisted of four steps:

1. We examined the link between narcissism and social activity in a Web community.

2. We inspected the associations between narcissism and the content of social networking Web pages. Consistent with past research on narcissistic self-regulation, narcissism should be associated with (a) a greater amount of social activity (Hypothesis 1) and (b) self-promotion in text and pictures (Hypothesis 2).

3. We tested whether individuals viewing a social networking page could detect the owner's expression of agentic/ communal traits and level of narcissism. Consistent with past research on personality and Web pages, we predicted that narcissism would be perceived by Web page observers, as would the general agentic qualities associated with narcissism (Hypothesis 3). As a corollary to this, we hypothesized that narcissistic Web page content would relate positively to observers' narcissistic impressions (Hypothesis 4).

4. We examined which social networking page content was the most influential in forming impressions of narcissism (i.e., mediational analyses, Hypothesis 5). Although it is reasonable to assume that there are elements of the Web page that lead viewers to judge the Web page owner's personality, we did not predict that one type of content or another would be more central in this process.

\section{METHOD}

\section{Participants}

Owners. Owner participants were 156 undergraduate Facebook page owners (100 females) participating for partial course credit. They ranged in age from 18 to 23 years $(M=18.97, S D=1.14)$. A total of $129(83 \%)$ gave permission to save their Facebook pages to be used in the present research. Those who did not give permission to save their Facebook pages were excluded from the main analyses.

Raters. Rater participants were 128 undergraduates (86 females) participating for partial course credit. They ranged in age from 18 to 26 years $(M=19.41, S D=1.59)$.

\section{Materials and Procedures}

Personality data and Facebook page collection. Owner participants came to the lab individually. Upon consenting to participate, they first completed demographic information and the Narcissistic Personality Inventory (NPI; Raskin \& Terry, 1988). The NPI is a 40-item forced-choice format personality questionnaire designed for use on a normal population. Example items include "My body is nothing special" versus "I like to look at my body" and "I am more capable than other people" versus "There is a lot that I can learn from other people." Higher scores on the NPI indicate more narcissistic personality (range $=2$ to $30, M=17.11$, $S D=6.00, \alpha=.78)$.

Second, participants were presented with a waiver form to sign if they consented to having their Facebook pages saved for this research project (129 agreed). The mean narcissism score for those participants who granted permission to save their Facebook Web pages $(M=17.14, S D=6.21)$ did not differ significantly from the mean narcissism score of those who did not grant permission $(M=16.67, S D=4.95), t(154)=-.37$, ns. Before signing the waiver form, participants were informed that if they gave permission to have their Facebook page saved, we would gather information from the page and other undergraduates would also view the page and report on the impressions they drew from it. Participants were also assured that before other undergraduates viewed their Facebook page, identifying information, such as last name, phone number, and e-mail address, would be deleted.

Third, if the participant declined, he or she was fully debriefed. If the participant granted permission to have his or her Facebook page saved, he or she was asked to $\log$ onto Facebook.com on a computer in the lab and display his or her main profile page on the Internet browser. An important distinction to point out is that owner participants were asked to display their Facebook profile page as opposed to their Facebook home page. The profile page is the page that others in their networks have access to viewing. The home page can be thought of as a control panel that only the owner has access to. The experimenter then saved the profile page. Participants were also asked to display the Web page linked to the profile page text View Photos of Me. This link displays 20 photographs. The first 12 are the most recent that the owner posted, regardless of which album they belong to. The second 8 are the most recent pictures that the owners' friends have uploaded and tagged the owner in. Tagging a photo on Facebook means that the photo will be linked to the tagged individual's profile page. Owners have the ability to accept or decline tags and therefore have control of all the pictures on the View Photos of $\mathrm{Me}$ link. The experimenter saved this page as well, and finally, the participants were fully debriefed.

Objective Facebook page coding. Objective criteria were extracted from the Facebook pages. These were quantitative features that are common to standard Facebook profiles. The four objective criteria were (a) number of friends $(M=171.21, S D=121.90)$, (b) number of wallposts $(M=479.94, S D=437.29)$, (c) number of groups $(M=35.17, S D=32.27)$, and (d) number of lines of text in the About Me section $(M=4.95, S D=8.75)$.

A quantity of social interaction measure was created by summing of the number of friends linked to the 
Facebook page (standardized) and the number of wallpost messages that were accumulated on the Facebook page (standardized) (range $=-2.44$ to $7.09, S D=1.79$, $\alpha=.75){ }^{3}$ A quantity of information about self measure was simply the number of lines of text that the owner had written in the section titled About $\mathrm{Me}(M=4.95$, $S D=8.75)$.

Subjective Facebook page coding by research assistant (RA) raters. Four features of the 129 saved Facebook pages were coded independently by five undergraduate RAs for the extent to which they were self-promoting. Each rater coded (a) the content of the About Me section, (b) the content of the Quotes section, (c) the main profile photograph (usually a headshot of the owner), and (d) the 20 pictures on the page linked to View Photos of Me. These four features were coded separately, that is, without the context of the other features present (e.g., the items from the About Me section and the Quotes section were pasted into separate documents and separated from the photos).

The contents of the About Me section were rated on the following characteristics: self-absorbed, self-conscious (reversed), self-important, and self-promoting. The contents of the Quotes section were rated on arrogant, clever, entertaining, and self-promoting. The main profile photograph was rated on the amount of clothing worn, modest (reversed), physically attractive, self-promoting, sexy, and vain. The pictures from the View Photos of Me link were rated on exciting, fun, modest (reversed), provocative, self-centered, and self-promoting. Importantly, prior to completing the coding, all of the RA coders met to agree on the definitions of the adjectives that each subjective feature was rated on. For example, self-promoting was distinguished from self-important in that self-promoting connoted persuading others about one's own positive qualities, whereas self-important expressed a statement about viewing one's self as important or as an individual with important opinions. All ratings were on a 7-point Likert scale ranging from 1 (not at all) to 7 (very much). The agreement of the five raters was sufficient (alphas ranging from .60 to .90, with the majority between .75 and .80 ). Thus, the means of the five RA raters' ratings were taken.

From the RA rater means, the following specific nine measures were created:

1. A measure of self-promoting information posted about self was created by taking the mean of the adjectives (across coders) that the About Me sections were rated on: self-absorbed, self-conscious (reversed), self-important, and self-promoting $(M=3.67, S D=.89, \alpha=.76)$.

2. A measure of self-promoting quotes was created by taking the mean of the coders' judgments of quote arrogance and self-promotion $(M=1.83, S D=.83, \alpha=.94)$.
3. A measure of entertaining quotes was created by taking the mean of the coders' ratings of how clever and entertaining the quotes seemed $(M=2.91, S D=.85, \alpha=.88)$.

4. The mean of the coders' judgments of the physical attractiveness of the owner's main photo served as the measure of main photo attractiveness $(M=3.88, S D=1.19)$.

5. A measure of main photo self-promotion was created by taking the mean of the coders' ratings of how selfpromoting and vain the photo was $(M=2.29, S D=.92$, $\alpha=.89$ ).

6. A measure of main photo sexiness was created by taking the mean of the coders' judgments of how sexy and modest (reversed) and clothed (reversed) the individual in the main photo appeared to be $(M=2.31, S D=.80$, $\alpha=.71)$.

7. A measure of self-promoting pictures was created by taking the mean of the coders' judgments of how selfcentered and self-promoting the pictures were $(M=2.46$, $S D=.97, \alpha=.95)$.

8. A measure of provocative pictures was created by taking the mean of the coders' judgments of how provocative and modest (reversed) the pictures were $(M=2.50$, $S D=.99, \alpha=.85)$.

9. A measure of fun pictures was created by taking the mean of the coders' judgments of how fun and exciting the pictures were $(M=3.70, S D=.73, \alpha=.88)$.

Facebook page impression ratings. Rater participants came to the lab individually. Upon consenting to participate, each was randomly assigned five Facebook pages that were collected from owners earlier in the study. Facebook page owners' identifying information (i.e., last names, e-mail addresses, and phone numbers) was removed from their Facebook pages. If the raters indicated that they had been assigned the Facebook page of someone they knew (a friend or acquaintance), they were told not to rate that page and it was replaced randomly with another.

Rater participants viewed the Facebook pages they were assigned one at a time and then rated the extent to which they believed the owner of the page possessed 37 different personality traits. Each rater rated only five Facebook pages to minimize fatigue and the potential for perceiver effects (Kenny, 1994). The personality traits that the raters used in their evaluations were drawn roughly from previous research (Campbell et al., 2007; Paulhus 1998; see the following). The pages were rated on a 7-point Likert scale ranging from 1 (not at all) to 7 (very much). From these ratings, we created three indices to measure raters' impressions of the Facebook owners' trait-level agency, communion, and narcissism. In computing these indices we examined the consistency of the five raters in their ratings of the adjectives comprising each index. Because the interrater reliabilities were sufficient (agency $\alpha=.92$, communion $\alpha=.92$, and narcissism $\alpha=.88$ ), we computed the means of the five raters' ratings for each of the 37 traits. 
An agentic impression composite was created by taking the mean of the raters' average impressions of Facebook page owners on the following traits: assertive, active, boring (reversed), confident, dominant, energetic, entertaining, enthusiastic, high in status, important, inhibited (reversed), intelligent, outspoken, quiet (reversed), reserved (reversed), silent (reversed), withdrawn (reversed), submissive (reversed) $(M=4.98$, $S D=.53, \alpha=.93)$.

A communal impression composite was created by taking the mean of the raters' average impressions of Facebook page owners on the following traits: affectionate, cooperative, cruel (reversed), friendly, generous, grouchy (reversed), hostile (reversed), kind, likeable, mean (reversed), pleasant, quarrelsome (reversed), rude (reversed), stingy (reversed), warm $(M=5.41, S D=.53$, $\alpha=.95$ ).

A narcissistic impression composite was created by taking the mean of the raters' average impressions of Facebook page owners on the following traits: arrogant, narcissistic, self-centered, vain $(M=2.75, S D=.80$, $\alpha=.92)$.

\section{RESULTS}

\section{Simple Correlations}

To test Hypothesis 1 that narcissism would predict social activity and the quantity of information posted about the self on Facebook pages, we correlated narcissism scores with the quantity of social interaction composite and the quantity of information about self (both measures of objective information drawn from Facebook pages that we collected from owner participants). ${ }^{4}$ As predicted, higher scores on the NPI were related to higher quantities of interaction on Facebook. No relationship was found between owners' narcissism scores and the quantity of information owners posted about themselves. ${ }^{5}$ (All correlations can be seen in Table 1.)

We next correlated owners' narcissism scores with RA coders' perceptions of Facebook profile features to test Hypothesis 2. First, owners' narcissism was correlated with the self-promoting information about self measure. A marginally significant positive relationship was found between owners' narcissism and the extent to which information posted about the owner in the About Me section was self-promoting. ${ }^{6}$ Second, owners' narcissism scores were correlated with the self-promoting quotes and entertaining quotes measures. Correlations revealed that those owners with high narcissism scores posted marginally more self-promoting quotes than those with low narcissism scores and their quotes were less entertaining and clever than those with low narcissism.
TABLE 1: Facebook Correlates With Owners' Narcissism Scores and Raters' Narcissistic Impression Ratings

\begin{tabular}{|c|c|c|}
\hline & $\begin{array}{c}\text { Owners' } \\
\text { Narcissism }\end{array}$ & $\begin{array}{c}\text { Raters' } \\
\text { Narcissistic } \\
\text { Impression }\end{array}$ \\
\hline \multicolumn{3}{|l|}{ Objective Facebook page criteria } \\
\hline Quantity of social interaction $(\alpha=.75)$ & $.23 * * *$ & $.31 * * *$ \\
\hline $\begin{array}{l}\text { Quantity of information listed about } \\
\text { self }\end{array}$ & .07 & $.29 * * *$ \\
\hline \multicolumn{3}{|l|}{$\begin{array}{l}\text { Subjective Facebook page criteria coded } \\
\text { by research assistant (RA) raters }\end{array}$} \\
\hline $\begin{array}{l}\text { Self-promoting information about } \\
\text { self }(\alpha=.76)\end{array}$ & $.18^{*}$ & $.32 * * *$ \\
\hline Self-promoting quotes $(\alpha=.94)$ & $.19 *$ & $.21 * *$ \\
\hline Entertaining quotes $(\alpha=.88)$ & $-.28 * * *$ & -.11 \\
\hline Main photo attractiveness & $.18 * *$ & $.33 * * *$ \\
\hline Main photo self-promotion $(\alpha=.89)$ & $.19 * *$ & $.37 * * *$ \\
\hline Main photo sexiness $(\alpha=.71)$ & $.20 * *$ & $.33 * * *$ \\
\hline Self-promoting pictures $(\alpha=.95)$ & .10 & $.28 * * *$ \\
\hline Provocative pictures $(\alpha=.85)$ & .07 & $.34 * * *$ \\
\hline Fun pictures $(\alpha=.88)$ & $.18 * *$ & $.17^{*}$ \\
\hline \multicolumn{3}{|l|}{ Impression ratings by participant raters } \\
\hline Communal impression $(\alpha=.95)$ & -.09 & $-.60 * * *$ \\
\hline Agentic impression $(\alpha=.93)$ & $.28 * * *$ & $.39 * * *$ \\
\hline Narcissistic impression $(\alpha=.92)$ & $.25 * * *$ & \\
\hline
\end{tabular}

$* p \leq .10 . * p \leq .05 . * * p \leq .01$.

We then examined the relationships between owners' narcissism and the contents of the images posted on the Facebook pages. First, narcissism scores were correlated with the main photo attractiveness, the main photo selfpromotion composite, and the main photo sexiness composite. Owners with higher NPI scores were seen as more physically attractive in their main photograph than those with low NPI scores. Likewise, in their main photograph, narcissistic owners also appeared to be sexier and more self-promoting than nonnarcissists as predicted by Hypothesis 2. Second, correlations were tested between owners' narcissism scores and the selfpromoting pictures, provocative pictures, and fun pictures measures. Narcissistic owners posted pictures that were more fun, but contrary to Hypothesis 2, they were not perceived to be significantly more provocative or self-promoting than nonnarcissistic owners' pictures.

Next, to assess Hypothesis 3 that observers can detect a Web page owner's self-reported narcissism by viewing his or her Facebook Web page, correlations were tested between owners' NPI scores and participant raters' narcissistic impression as well as agentic impression and communal impression. As predicted, narcissistic Facebook page owners were perceived to be more narcissistic. In addition, narcissism was associated with a pattern of high perceived agency and no link to perceived communion, very similar to the relationship found in narcissists' explicit and implicit self-ratings (Campbell et al., 2007; Campbell, Rudich, et al., 2002). 
According to the magnitude of these correlations, the association between owners' NPI scores and raters' agentic impression scores was stronger than that between owners' NPI scores and raters' narcissistic impressions. To determine if raters' perception of narcissism was fully cued by the perception of agency, owners' NPI scores were regressed onto raters' narcissistic impression and agentic impression simultaneously. A significant coefficient for agentic impression, $\beta=.21, t(125)=2.31, p=.02$, and a marginally significant coefficient for narcissistic impression, $\beta=.16, t(125)=1.75, p=.08$, resulted, indicating that raters' perceptions of both agency and narcissism accounted for unique variance (at least marginally) in owners' narcissism.

Finally, we tested the prediction set forth in Hypothesis 4 that Web page content indicative of narcissism would relate positively to raters' narcissistic impressions. First, we correlated raters' narcissistic impressions with the objective information drawn from the owners' Facebook pages. As predicted, higher narcissistic impression ratings were related to higher quantities of social interaction on Facebook and higher quantities of information posted about the self.

Second, correlations between raters' narcissistic impressions and RA coders' subjective ratings of the written information on the Facebook pages were tested. In accord with Hypothesis 4, a significant positive relationship was found between raters' narcissistic impression and the extent to which self-promoting information about self was posted. Raters' narcissistic impressions were also positively associated with self-promoting quotes but not related to the entertaining quotes measure.

Third, we examined the relationships between raters' narcissistic impressions and the contents of the images posted on the owners' Facebook pages. Owners who were judged to be more narcissistic were seen as more physically attractive in their main photograph, sexier, and more self-promoting than those viewed as less narcissistic. Raters' narcissistic impressions were also positively related to posting pictures that were perceived to be more self-promoting, more provocative, and more fun, as predicted by Hypothesis 4 .

\section{Mediation Analyses}

We have established that owners' narcissistic personality relates to objective and subjective Facebook page content. We have also shown that impressions of narcissism based on solely viewing Facebook pages are somewhat accurate and that the content features that are linked with owners' narcissism also generally correlate with raters' narcissistic impression. We now test Hypothesis 5 to determine whether Facebook page content features mediate the link between owners' narcissistic personality and raters' narcissistic impression drawn from Facebook page observations. We also ask: If mediation occurs, what content of Web pages is influential in observers' detection of narcissism?

All of the Facebook page content features that correlated significantly $(p<.05)$ with both narcissistic personality scores and raters' narcissistic impression scores were considered potential mediators, including (a) quantity of social interaction, (b) main photo attractiveness, (c) main photo sexiness, and (d) main photo self-promotion. To determine whether together these four Facebook page content mediators fully mediated the relationship between owners' narcissism and raters' narcissistic impression, bootstrapping analyses were conducted using methods described by Preacher and Hayes (2007) for estimating direct and indirect effects with multiple mediators. There are three advantages to using this statistical method: (a) Multiple mediators can be tested simultaneously, (b) it does not rely on the assumption of a normal sampling distribution (see MacKinnon, Lockwood, \& Williams, 2004; Preacher \& Hayes, 2004; Shrout \& Bolger, 2002), and (c) the number of inferential tests is minimized, thus reducing the likelihood of Type 1 error. Raters' narcissistic impression was entered as the dependent variable, owners' narcissism was entered as the predictor variable, and quantity of social interaction, main photo attractiveness, main photo sexiness, and main photo self-promotion were entered as proposed mediators in the SPSS macro created by Preacher and Hayes for bootstrap analyses with multiple proposed mediators.

The bootstrap results indicated that the total effect of owners' narcissism scores on raters' narcissistic impression (total effect $=.03, p=.01$ ) became nonsignificant when the Facebook page content mediators were included in the model (direct effect of owners' narcissism $=.02, n s$ ). Furthermore, the analyses revealed, with $95 \%$ confidence, that the total indirect effect (i.e., the difference between the total and direct effects) of owners' narcissism on the outcome variable through the four mediators was significant, with a point estimate of .02 and a $95 \%$ BCa (bias-corrected and accelerated; see Efron, 1987) bootstrap confidence interval of .0070 to .0305 . Thus, the four Facebook page content characteristics fully mediated the association between owners' narcissism and raters' narcissistic impression. The specific indirect effects of each proposed mediator showed that quantity of social interaction, with a point estimate of .0052 and $95 \%$ BCa CI of .0010, .0154; main photo attractiveness, with a point estimate of .0088 and $95 \%$ BCa CI of $.0002, .0138$; and main photo self-promotion, with a point estimate of .0044 and $95 \%$ BCa CI of .0019, .0235 were all unique mediators; whereas main photo sexiness, with a 


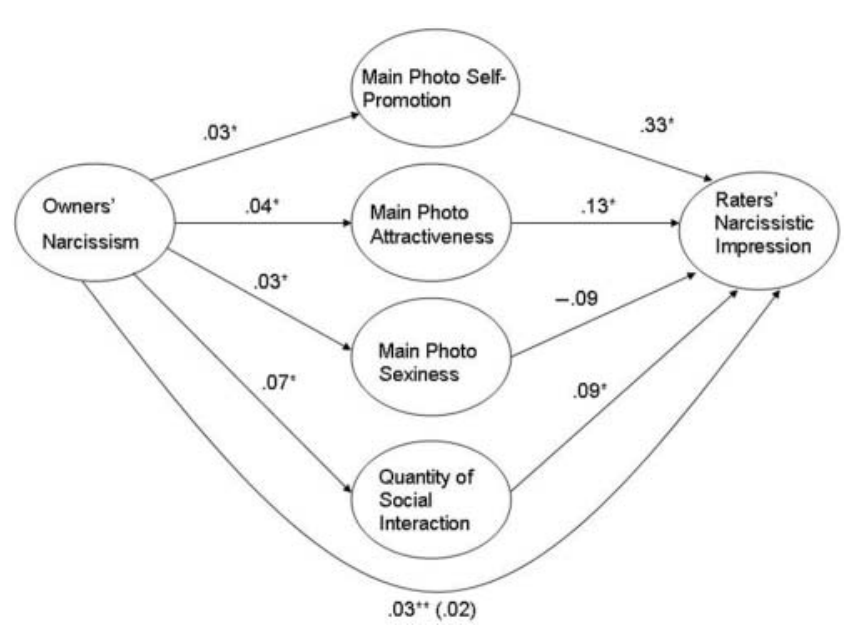

Figure 1 Facebook page content mediators of narcissism-narcissistic impression link.

NOTE: Path values represent unstandardized regression coefficients. The value outside of the parentheses represents the total effect of narcissism on narcissistic impression prior to the inclusion of the mediating variables. Value in parentheses represents the direct effect, from bootstrapping analyses, of narcissism on narcissistic impression after the mediators are included. $* p<.05 . * p<.01$.

point estimate of -.0023 and $95 \%$ BCa CI of -.0149 , .0048 , did not add to the overall model. ${ }^{7}$

In sum, the bootstrap analyses indicate that (a) quantity of social interaction, (b) main photo attractiveness, and (c) main photo self-promotion together mediate the link between Facebook page owners' narcissistic personality and Facebook page viewers' ratings of their narcissistic impression of the owners (see Figure 1 for full mediational model).

\section{DISCUSSION}

Is the narcissism of a Web page owner in a social networking community related to Web site activity, content, and perception by others? It appears that this is the case. In terms of objective criteria on the Web page, narcissism is related to a measure of Web site activity derived from the number of friends and the number of wallposts (i.e., messages) posted between friends. Narcissism was not found to be related to length of self-description on the Web page, however. In terms of the RA coder ratings of Web page written content, narcissism is positively (but only marginally) related to self-promoting information about the self and quotes and negatively related to entertaining quotes (this latter finding is interesting in that it differs from related findings in direct social interaction; e.g., Paulhus, 1998). Similarly, in terms of coder ratings of Web page image content, narcissism is positively associated with main photograph attractiveness, self-promotion, and sexiness. There were fewer relationships with the other photo album pictures, which were judged to be more fun but not more self-promoting or provocative. Although the sizes of these effects are small, given the complexity and the nuances of Facebook profiles, they are notable.

In terms of overall impression of the social networking Web page, strangers rated narcissistic individuals as more agentic (but not more communal) and more narcissistic, and furthermore, their impressions of narcissism and agency uniquely predicted Web page owners' narcissism. Narcissistic impressions were related to all of the Facebook page content features that narcissistic personality scores were related to as well as three additional features, namely, the quantity of information listed about self, self-promoting pictures, and provocative pictures. Finally, mediational analyses revealed that the impression of narcissism is based primarily on the number of social interactions along with the extent to which the Web page owner appears to be self-promoting and attractive in his or her main photo.

\section{Implications}

This research has several implications both for narcissism and for Web page-mediated social interaction. First, the expression of narcissism on social networking Web sites is very similar to its expression in other social domains. Narcissism is related to a higher number of social relationships, self-promoting self-presentation, and the perception of having a large number of agentic characteristics. Only two differences were found between narcissism in the "real world" and in online communities. The narcissists' quotes were judged to be less entertaining than those of nonnarcissists. This contrasts with the general finding that narcissists are entertaining at first meeting (e.g., Paulhus, 1998). We would like to point out that our incongruent finding, however, is not sufficient to suggest that narcissists' ability to entertain others in social contexts is subdued online. Rather, it is possible that narcissists' quotes are actually quite entertaining to peers who know their context but not to our RA coders who were not acquainted with the profile owners personally. Based on our findings, it is also plausible that the extent to which the narcissists' quotes and other aspects of their profiles were viewed as selfpromoting directly interfered with the quotes' entertainment and cleverness. Therefore, additional research in which the entertainment value of narcissists' full profile, rather than just the quotes section, is necessary to determine whether narcissists are less entertaining in online contexts than in face-to-face ones. In addition, the narcissists were judged to be more attractive based on their photos than the nonnarcissists. This differs from past research that has found no differences in attractiveness 
between narcissists and nonnarcissists (Gabriel et al., 1994). Why this disparity? One possible explanation is that narcissists' self-enhancing biases might lead them to consider more attractive pictures of themselves to be more accurate representations of their true likenesses. We would also speculate, however, that the narcissists appear to be attractive on Facebook because they are strategically posting pictures that make them appear sexy and attractive; this was not an option in Gabriel and colleagues' (1994) study.

Second, unacquainted raters are able to judge Web page owners' narcissism with some level of accuracy. This finding is consistent with those concerning the accuracy of Big Five personality perception based on viewing Web pages (Marcus et al., 2006; Vazire \& Gosling, 2004) in that Web page viewers can make reasonable estimates of personality from Web pages. More broadly, the correlation between self-reported narcissism and strangers' impressions of narcissism also suggests that at least on Facebook, less narcissistic participants do not seem to be using the Internet as a channel for selfpromotion. That is, more modest, less self-centered individuals in real life do not appear to be self-promoting to the degree that narcissists are on the Web.

Third, our results indicate that, as in past Big Five research (Marcus et al., 2006), viewers use Web page content to form impressions of the Web page owner's level of narcissism. We found that the quantity of social interaction and main photo in particular played a significant role in this process. Conversely, the raters seemed to have omitted other Facebook features that related to NPI scores, including self-promoting information about the self, self-promoting quotes, less entertaining quotes, main photo sexiness, and fun pictures, in their impression formation. Finally, narcissistic impression ratings related (falsely) to three profile characteristics that did not correlate with owners' narcissistic personality, namely, quantity of information listed about the self, self-promoting pictures, and provocative pictures. This pattern in raters' errors of omission and commission preliminarily suggests that individuals who have experience with social networking Web sites, as presumably our raters did, may have developed a system or script (Schank \& Abelson, 1977) for viewing such Web pages and efficiently gleaning important information for the context of a social networking community. It is understandable, if this is the case, that an individual's social capital (how popular and socially active they are quantifiably) and attractiveness, which both can be determined quickly, play an important role in impression formation, as our results suggest. In contrast, the somewhat more difficult to decipher written information, such as that in the About Me and Quotes sections, may be secondary. This remains speculative, however, and might be an interesting avenue for future research.

Fourth, there are some interesting applied implications that potentially stem from the aforementioned findings. For example, the findings imply that the network of individuals on social networking Web sites will contain a relatively high percentage of narcissistic individuals. Specifically, because narcissists have more social contacts on Facebook than the nonnarcissists, the average user will experience a social network that overrepresents narcissists. This would be important information for social networking site users to be aware of. It also raises the possibility that-because of elevated exposure to narcissistic individuals and self-promotionnorms of expression on social networking sites will be pulled in the direction of greater self-promotion. Another possible application of this research pertains to individuals who are considering entering into a romantic relationship with someone they meet on a social networking site might be able to detect trait narcissism. Given what is known from past research about the negative tendencies of narcissists in relationships (e.g., Campbell, 1999; Campbell, Foster, et al., 2002), this would be valuable information. Though these are stimulating possibilities, the applied applications of this research should be read with considerable caution due to the small effect sizes that resulted in our findings.

Fifth, if narcissists use social networking sites as an outlet for maintaining their inflated, positive self-views, and if those who use social networking Web sites are exposed to a heightened level of narcissistic personality, do these Internet communities contribute to rising levels of narcissism over time? Based on the evidence adduced in this research, we cannot answer this question. Participating in social networking online is arguably attractive to narcissists in that it allows for controlled self-presentation, satiates the craving for attention, and promotes shallow relationships, all of which are associated with narcissism. Thus, one might argue that using social networking Web sites can aid in regulating narcissists' inflated positive self-views. Yet, it remains unclear whether or not social networking on the Internet results in an increase in dispositional narcissism for individuals with low narcissism scores. To appropriately address this question, we believe we need a program of converging research methods (e.g., user vs. nonuser comparisons as in Marcus and colleagues' [2006] work; longitudinal research, i.e., examinations of the change in narcissism scores of Internet users over time; and controlled experimental research, e.g., manipulating Web site usage and assessing short- and long-term personality change). There is clearly a good deal of research to be done on Internet usage and personality. 
Sixth and finally, we believe that this study makes an important contribution to psychological methodology. In the present investigation, our main variable of interest was narcissism, but we believe that with some modifications, these methods could be employed in studying an array of individual difference variables. Key to our approach was supplementing impressions of the overall Web page made by participant raters with two types of information drawn from social networking Web pages: (a) objective profile measures (e.g., number of friends) and (b) coders' ratings of subjective aspects made in isolation from the other information on the page. The objective measures are currently limited in number, though arguably constantly increasing due to the innovations being made in social networking communities. However, there is an almost unlimited amount of information that can be obtained from coders' ratings of more subjective aspects of social networking profiles. In combination, these two information extraction strategies represent a good deal of flexibility for future personality research. For example, our methods could easily be adapted to study individual differences like attachment styles (Hazan \& Shaver, 1987), need for belongingness (Baumeister \& Leary, 1995), rejection sensitivity (Downey \& Feldman, 1996), self-monitoring (Snyder, 1987), or social anxiety (Leary, 1983). Furthermore, our method could also be viewed as a starting point for developing new ways to study broader, natural social systems as well as more general theoretical issues, such as perceiver accuracy and consensus (Kenny, 1994), self-observer agreement (Funder, 1980), and cue utilization in impression formation (Brunswik, 1956). In particular, researchers interested in how accurately individuals perceive information presented on Web pages would benefit from using the Brunswik (1956) approach.

\section{Caveats}

Two limitations of the present research need to be addressed. The first concerns the characteristics of our sample. Our sample was not diverse in age. The participants were all college students. Moreover, we only assessed activity and presentation on Facebook.com and have not examined the variety of other social networking sites available. Personality may potentially be presented and perceived somewhat differently on Web sites like MySpace.com as they are more customizable both in the aesthetics of the page and the available features.

Second, we examined perceptions of narcissism made by strangers but not other individuals (e.g., friends, potential employers). Unlike other Web-based interpersonal contact (e.g., discussion boards, newsgroups, chatrooms), communication on social networking Web sites is for the most part not anonymous. The primary goal of interaction on social networking Web sites is to strengthen bonds and keep in touch with friends made in the real, offline world. Past research has shown that communicating on the Internet with individuals whom one has never met before in person may be a venue for freely expressing the true self (Bargh, McKenna, \& Fitzsimons, 2002; Spears \& Lea, 1994). In contrast, because they are not anonymous, individuals may be motivated to maintain offline images and fulfill social roles and the obligations that come with them on social networking sites (Burke, 1980; Burke \& Tully, 1977). This raises two further questions about presenting and perceiving narcissistic personality on the Internet. First, do individuals view their narcissistic friends as more narcissistic when they view their personal Web pages as compared to when they interact face to face? Second, as compared to an anonymous online environment, is it possible that narcissists tone down the extent to which they self-enhance and self-promote in a social networking community? Further research is required to provide answers to these remaining questions.

\section{Conclusion}

Today, interaction and self-presentation on the Internet are the norm. Maintaining a Web presence and keeping in contact with a large number of individuals via social networking Web sites has become part of many individuals' daily lives. In the present study, our goal was to examine how trait narcissism is expressed on Webbased social networks. The results demonstrate that narcissists act, portray themselves, and are perceived on social networking sites in a manner similar to how they behave in real, offline life. We hope that these initial findings spur future inquiry into the manifestations of narcissism and other personality variables on social networking sites and other locations on the Internet.

\section{NOTES}

1. Women with personal Web sites reported higher narcissism scores than those without personal Web sites; men with and without Web sites had similar narcissism scores (and the men's narcissism scores were similar to the women Web site owners' narcissism scores).

2. Narcissism, as we are examining the construct, refers to a continuous, nontaxonic normal personality variable (Foster \& Campbell, 2007). This is distinct from narcissistic personality disorder (NPD) described in the Diagnostic and Statistical Manual of Mental Disorders (American Psychiatric Association, 1994). Nevertheless, trait narcissism, as we operationalize it with the Narcissistic Personality Inventory (NPI), does correlate significantly with clinicians' and clinical researchers' prototypes of NPD (Miller \& Campbell, 2008). We use the term narcissists in some instances as a shorthand for "high narcissism scores." This is done in the interest of improved readability.

3. Originally, we included the number of groups (standardized) in the quantity of social interaction composite. Including this measure, however, created a low level of internal consistency $(\alpha=.54)$. 
Therefore, we elected to drop the number of groups from the composite. We should report, however, that when number of groups was included, the results of the analyses performed on it remained the same. Quantity of social interaction correlated with narcissism, $r(127)=.19$, $p=.03$, and with narcissistic impression, $r(126)=.25, p<.01$.

4. These objective measures were not limited in range and therefore susceptible to positive skew. We addressed the possibility of nonnormality by $\log$ transforming (Winer, 1971) the following measures: number of friends, number of wallposts, and quantity of information posted about self. The quantity of social interaction composite measure that was used in the main analyses could not be log transformed because it is standardized. Importantly, when the transformed scores were correlated with NPI scores, a similar pattern of results was obtained such that the number of friends and narcissism were positively correlated, $r(128)=.25, p=.01$, and greater quantities of wallposts were marginally related to greater NPI scores, $r(127)=.15, p=.09$. Furthermore, neither the magnitude of the correlation between transformed number of friends and NPI nor between transformed number of wallposts and NPI significantly differ from the correlation between quantity of social interaction and NPI scores, $t s<1.23$, ns. Also, the logtransformed quantity of information posted about self scores were not correlated with NPI scores, $r(78)=.03, n s$, as in the main analyses.

5 . When controlling for gender, the correlations between narcissism and each objective, subjective, and impression measure remained the same with one exception. That is, all significant correlations presented in this section remain significant and all nonsignificant correlations remain nonsignificant except for the association between narcissism and self-promoting information about self. This correlation became nonsignificant, $\beta=.17, t(75)=1.03$, ns. In addition to this, gender was a significant predictor in three models-quantity of social interaction, $\beta=.28, t(124)=3.37, p=.001$; main photo attractiveness, $\beta=.21, t(125)=2.42, p=.02$; and fun pictures, $\beta=.21$, $t(124)=2.48, p=.01$-such that females were higher on all three of these measures.

6. The $N$ in this correlation is lower than in other tests because only 79 of 129 Web page owners included About Me sections on their Facebook profiles. The mean narcissism score for those participants who included About Me sections $(M=17.81, S D=6.04)$ did not differ significantly from the mean narcissism score of those who did not $(M=16.12, S D=6.38), t(127)=-1.52, n s$.

7. We also tested each of the four combined mediators in separate mediational models using Baron and Kenny's (1986) recommended procedure. Although none fully mediated the link between owners' narcissism and raters' narcissistic impression, all four of the content features-quantity of social interaction, main photo attractiveness, main photo sexiness, and main photo self-promotion-each partially mediated this association. The Sobel (1982) tests for each of these models was also significant, with the exception of the model including main photo attractiveness, for which the Sobel test was marginally significant.

\section{REFERENCES}

American Psychiatric Association. (1994). Diagnostic and statistical manual of mental disorders (4th ed.). Washington, DC: Author.

Baldwin, T., \& Stroman, A. (2007, March 1). How self-esteem classes are "breeding selfish generation." The Times London. Retrieved May 14, 2007, from http://www.timesonline.co.uk/tol/news/uk/ education/article1455519.ece

Bargh, J. A., McKenna, K. Y. A., \& Fitzsimons, G. M. (2002). Can you see the real me? Activation and expression of the "true self" on the Internet. Journal of Social Issues, 58, 33-48.

Baron, R. M., \& Kenny, D. A. (1986). The moderator-mediator variable distinction in social psychological research: Conceptual, strategic and statistical considerations. Journal of Personality and Social Psychology, 51, 1173-1182.

Baumeister, R. F., \& Leary, M. R. (1995). The need to belong: Desire for interpersonal attachments as a fundamental human motivation. Psychological Bulletin, 117, 497-529.
Brown, R. P., \& Zeigler-Hill, V. (2004). Narcissism and the nonequivalence of self-esteem measures: A matter of dominance? Journal of Research in Personality, 38, 585-592.

Brunell, A. B., Campbell, W. K., Smith, L., \& Krusemark, E. A. (2004, February). Why do people date narcissists? A narrative study. Poster session presented at the annual meeting of the Society for Personality and Social Psychology, Austin, TX.

Brunell, A. B., Gentry, W., Campbell, W. K., \& Kuhnert, K. (2006, January). Narcissism and emergent leadership. Poster session presented at the annual meeting of the Society for Personality and Social Psychology, Palm Springs, CA.

Brunswik, E. (1956). Perception and the representative design of psychological experiments. Berkeley: University of California Press.

Burke, P. J. (1980). The self: Measurement requirements from an interactionist perspective. Sociometry, 43, 18-29.

Burke, P. J., \& Tully, J. (1977). Reconstructing social identity. Personality and Social Psychology Bulletin, 19, 4-5.

Bushman, B. J., \& Baumeister, R. F. (1998). Threatened egotism, narcissism, self-esteem, and direct and displaced aggression: Does selflove or self-hate lead to violence? Journal of Personality and Social Psychology, 75, 219-229.

Buss, D. M., \& Chiodo, L. M. (1991). Narcissistic acts in everyday life. Journal of Personality, 59, 179-215.

Campbell, W. K. (1999). Narcissism and romantic attraction. Journal of Personality and Social Psychology, 77, 1254-1270.

Campbell, W. K., Bonacci, A. M., \& Shelton, J. (2004). Psychological entitlement: Interpersonal consequences and validation of a selfreport measure. Journal of Personality Assessment, 83, 29-45.

Campbell, W. K., Bosson, J. K., Goheen, T. W., Lakey, C. E., \& Kernis, M. H. (2007). Do narcissists dislike themselves "deep down inside"? Psychological Science, 18, 227-229.

Campbell, W. K., Brunell, A. B., \& Finkel, E. J. (2006). Narcissism, interpersonal self-regulation, and romantic relationships: An agency model approach. In E. J. Finkel \& K. D. Vohs (Eds.), Self and relationships: Connecting intrapersonal and interpersonal processes (pp. 57-83). New York: Guilford.

Campbell, W. K., \& Foster, C. A. (2002). Narcissism and commitment in romantic relationships: An investment model analysis. Personality and Social Psychology Bulletin, 28, 484-495.

Campbell, W. K., Foster, C. A., \& Finkel, E. J. (2002). Does self-love lead to love for others? A story of narcissistic game playing. Journal of Personality and Social Psychology, 83, 340-354.

Campbell, W. K., Rudich, E., \& Sedikides, C. (2002). Narcissism, selfesteem, and the positivity of self-views: Two portraits of self-love. Personality and Social Psychology Bulletin, 28, 358-368.

Carroll, L. (1987). A study of narcissism, affiliation, intimacy, and power motives among students in business administration. Psychological Reports, 61, 355-358.

Downey, G., \& Feldman, S. I. (1996). Implications of rejection sensitivity for intimate relationships. Journal of Personality and Social Psychology, 70, 1327-1343.

Efron, B. (1987). Better bootstrap confidence intervals. Journal of the American Statistical Association, 82, 171-185.

Emmons, R. A. (1984). Factor analysis and construct validity of the Narcissistic Personality Inventory. Journal of Personality Assessment, 48, 291-300.

Foster, J. D., \& Campbell, W. K. (2007). Are there such things as "narcissists" in social psychology? A taxometric analysis of the Narcissistic Personality Inventory. Personality and Individual Differences, 43, 1321-1332.

Foster, J. D., Shrira, I., \& Campbell, W. K. (2003, June). The trajectory of relationships involving narcissists and non-narcissists. Poster session presented at the annual meeting of the American Psychological Society, Atlanta, GA.

Foster, J. D., Shrira, I., \& Campbell, W. K. (2006). Theoretical models of narcissism, sexuality, and relationship commitment. Journal of Social and Personal Relationships, 23, 367-386.

Funder, D. C. (1980). On seeing ourselves as others see us: Self-other agreement and discrepancy in personality ratings. Journal of Personality, 48, 474-493. 
Gabriel, M. T., Critelli, J. W., \& Ee, J. S. (1994). Narcissistic illusions in self-evaluations of intelligence and attractiveness. Journal of Personality, 62, 143-155.

Geist, M. (2007, May 9). Facing up to Facebook fears. BBC News. Retrieved May 10, 2007, from http://news.bbc.co.uk/2/hi/ technology/6639417.stm

Hazan, C., \& Shaver, P. (1987). Romantic love conceptualized as an attachment process. Journal of Personality and Social Psychology, $52,511-524$

John, O. P., \& Robins, R. W. (1994). Accuracy and bias in self-perception: Individual differences in self-enhancement and the role of narcissism. Journal of Personality and Social Psychology, 66, 206-219.

Kenny, D. A. (1994). Interpersonal perception: A social relations analysis. New York: Guilford.

Kirkpatrick, D. (2007, May 24). Facebook's plan to hook up the world. Fortune. Retrieved June 5, 2007, from http://money.cnn .com/2007/05/24/technology/facebook.fortune/index.htm

Le, T. N. (2005). Narcissism and immature love as mediators of vertical individualism and ludic love style. Journal of Social and Personal Relationships, 22, 542-560.

Leary, M. R. (1983). Social anxiousness: The construct and its measurement. Journal of Personality Assessment, 47, 66-75.

Locke, L. (2007, July 17). The future of Facebook. Time. Retrieved December 13, 2007, from http://www.time.com/time/business/ article/0,8599,1644040,00.html

MacKinnon, D. P., Lockwood, C. M., \& Williams, J. (2004). Confidence limits for the indirect effect: Distribution of the product and resampling methods. Multivariate Behavioral Research, 39, 99-128.

Marcus, B., Machilek, F., \& Schütz, A. (2006). Personality in cyberspace: Personal websites as media for personality expressions and impressions. Journal of Personality and Social Psychology, 90, 1014-1031.

Miller, J. D., \& Campbell, W. K. (2008). Comparing clinical and social-personality conceptualizations of narcissism. Journal of Personality, 76, 449-476.

Miller, J. D., Campbell, W. K., \& Pilkonis, P. A. (2007). Narcissistic personality disorder: Relations with distress and functional impairment. Comprehensive Psychiatry, 48, 170-177.

Morf, C. C., \& Rhodewalt, F. (2001). Unraveling the paradoxes of narcissism: A dynamic self-regulatory processing model. Psychological Inquiry, 12, 177-196.

Orlet, C. (2007, March 2). The look-at-me generation. The American Spectator. Retrieved May 14, 2007, from http://www.spectator .org/dsp_article.asp?art_id=11093

Oltmanns, T. F., Friedman, J. N., Fiedler, E. R., \& Turkheimer, E. (2004). Perceptions of people with personality disorders based on thin slices of behavior. Journal of Research in Personality, 38, 216-229.

Paulhus, D. L. (1998). Interpersonal and intrapsychic adaptiveness of trait self-enhancement: A mixed blessing? Journal of Personality and Social Psychology, 74, 1197-1208.

Paulhus, D. L., \& Williams, K. (2002). The dark triad of personality: Narcissism, Machiavellianism, and psychopathy. Journal of Research in Personality, 36, 556-568.

Preacher, K. J., \& Hayes, A. F. (2004). SPSS and SAS procedures for estimating indirect effects in simple mediation models. Behavior Research Methods, Instruments, \& Computers, 36, 717-731.
Preacher, K. J., \& Hayes, A. F. (2007). Asymptotic and resampling strategies for assessing and comparing indirect effects in simple and multiple mediation models. Manuscript submitted for publication.

Raskin, R., Novacek, J., \& Hogan, R. (1991). Narcissism, selfesteem, and defensive self-enhancement. Journal of Personality, 59, 19-38.

Raskin, R., \& Terry, H. (1988). A principal-components analysis of the Narcissistic Personality Inventory and further evidence of its construct validity. Journal of Personality and Social Psychology, 54, 890-902.

Robins, R. W., \& John, O. P. (1997). Effects of visual perspective and narcissism on self-perception: Is seeing believing? Psychological Science, 8, 37-42.

Schank, R. C., \& Abelson, R. P. (1977). Scripts, plans, goals and understanding: an inquiry into buman knowledge structures. Hillsdale, NJ: Lawrence Erlbaum.

Schmitt, D. P., \& Buss, D. M. (2001). Human mate poaching: Tactics and temptations for infiltrating existing relationships. Journal of Personality and Social Psychology, 80, 894-917.

Shrout, P. E., \& Bolger, N. (2002). Mediation in experimental and nonexperimental studies: New procedures and recommendations. Psychological Methods, 7, 422-445.

Snyder, M. (1987). Public appearances as private realities: The psychology of self-monitoring. New York: Freeman.

Sobel, M. E. (1982). Asymptotic confidence intervals for indirect effects in structural equation models. In S. Leinhardt (Ed.), Sociological methodology 1982 (pp. 290-312). Washington, DC: American Sociological Association.

Spears, R., \& Lea, M. (1994). Panacea or panopticon? The hidden power in computer-mediated communication. Communication Research, 21, 427-459.

Stone, B. (2007, March 20). MySpace restrictions upset some users. The New York Times. Retrieved May 10, 2007, from http://www .nytimes.com/2007/03/20/technology/20myspace.html?ei=5124\& en $=8 \mathrm{e} 52 \mathrm{c} 7873 \mathrm{eb} 73159 \& \mathrm{ex}=1332043200 \&$ pagewanted $=$ all

Vaidhyanathan, S. (2006, December 28). Me, "Person of the Year"? No thanks. MSNBC.com. Retrieved May 14, 2007, from http://www .msnbc.msn.com/id/16371425/

Vazire, S., \& Funder, D. C. (2006). Impulsivity and the self-defeating behavior of narcissists. Personality and Social Psychology Review, 10, 154-165.

Vazire, S., \& Gosling, S. D. (2004). e-perceptions: Personality impressions based on personal websites. Journal of Personality and Social Psychology, 87, 123-132.

Young, S. M., \& Pinsky, D. (2006). Narcissism and celebrity. Journal of Research in Personality, 40, 463-471.

Wallace, H. M., \& Baumeister, R. F. (2002). The performance of narcissists rises and falls with perceived opportunity for glory. Journal of Personality and Social Psychology, 82, 819-834.

Winer, B. (1971). Statistical principles in experimental design. New York: McGraw-Hill.

Received August 14, 2007

Revision accepted February 19, 2008 